\title{
A INFLUÊNCIA HEGELIANA DO RECONHECIMENTO EM CHARLES TAYLOR E AXEL HONNET NA CONTEMPORANEIDADE
}

\author{
José Aldo Camurça de Araújo Neto ${ }^{1}$
}

\begin{abstract}
Resumo:
O presente artigo pretende analisar a categoria reconhecimento nas filosofias de Charles Taylor e Axel Honneth. O tema em questão apresenta relevância na contemporaneidade pelo fato da existência de grupos sociais, entidades ditas minoritárias que desejam mais espaços públicos de discussão a fim de terem seus direitos reconhecidos, efetivados. Nesse sentido, faz-se necessário inserir na discussão dois autores atuais que tratam do assunto reconhecimento em seus sistemas filosóficos. Não por acaso que o fio condutor adotado neste escrito são os escritos juvenis de Hegel em Iena. Isso porque a filosofia deste autor alemão traz a intersubjetividade como elemento central na presente discussão. Dito de outro modo, a construção especulativa desta mediação propicia a efetivação da ideia de liberdade e, consequentemente, a possível concretização da ideia de vida ética comunitária. Nesse ponto, os autores contemporâneos se aproximam no que tange a essa tentativa de analisar as mediações desse tipo de reconhecimento para a sociedade atual. Ainda assim, os mesmos possuem algumas diferenças que a presente argumentação pretende desenvolver.
\end{abstract}

Palavras-Chave: Reconhecimento. Intersubjetividade. Liberdade.

\section{THE HEGELIAN INFLUENCE OF RECOGNITION IN CHARLES TAYLOR AND AXEL HONNETH IN CONTEMPORARY}

\begin{abstract}
:
The present article intends to analyze the category recognition in the philosophies of Charles Taylor and Axel Honneth. The issue in question is relevant in contemporary times because of the existence of social groups, so-called minority entities that want more public spaces of discussion in order to have their rights recognized, effective. In this sense, it is necessary to insert in the discussion two current authors who deal with the subject recognition in their philosophical systems. It is not by chance that the guiding principle adopted in this writing is Hegel's juvenile writings in Iena. This is because the philosophy of this German author brings intersubjectivity as the central element in the present discussion. In other words, the speculative construction of this mediation leads to the realization of the idea of freedom and, consequently, the possible realization of the idea of community ethical life. At this point, the contemporary authors are approaching in this attempt to analyze the mediations of this type of recognition for today's society. Even so, they have some differences that the present argument intends to develop.
\end{abstract}

Key words: Recognition. Intersubjectivity. Freedom.

1 Doutor em Filosofia pela Universidade Federal do Ceará (UFC). Professor Substituto da Universidade Estadual do Ceará (UECE). Professor Efetivo da Educação Básica do Ceará (SEDUC). Contato: aldolike@gmail.com / nossopais2005@yahoo.com.br 


\section{1-Introdução}

A discussão contemporânea assiste à retomada do pensamento hegeliano a partir de novos padrões conceituais. O solo desta retomada refere-se aos padrões com os quais o pensamento hegeliano é reatualizado. Dois exemplos de autores atuais que tentam fazer tal retomada são Charles Taylor (1931-) e Axel Honneth (1949-).

O primeiro, canadense, é considerado um dos grandes teóricos do campo moral e político da contemporaneidade. O segundo, alemão, possui a sua relevância em um mundo complexo, multifacetado como o nosso. Tais autores são importantes pela discussão fundamental e necessária acerca da categoria reconhecimento. Mesmo porque para que ocorra uma intersubjetividade pressupõe-se uma aceitação de liberdades ou mesmo encontrar uma identidade que possa unir pessoas de diferentes concepções, posturas.

Além desse aspecto, emerge a necessidade de uma interação entre duas ou mais vontades a fim de que haja uma efetivação. Mesmo assim essa interação não basta, pois nem sempre as vontades são equivalentes, livres ${ }^{2}$. Por esse motivo que a expressão reconhecimento se tornou um conceito central da teoria social contemporânea. Taylor e Honneth possuem contribuições decisivas para este debate.

Ora, a exigência de entender a identidade moderna é o verdadeiro insight da reflexão de ambos os autores. Isso se justifica pelo fato dos dois autores tentarem compreender os momentos de rupturas na história da civilização ocidental, oferecendo evidências de que a nossa identidade, tanto de grupos quanto de indivíduos, revela um rico e articulado substrato axiológico a ser explorado ${ }^{3}$.

Não por acaso a tentativa de Taylor e Honneth de imprimirem uma "marca" conceitual ao tema do reconhecimento. O primeiro analisa o termo a nível do multiculturalismo; o segundo pressupõe a análise de sua filosofia a partir das experiências negativas de desrespeito que geram, por conseguinte, os momentos de reconhecimento.

2 Segundo Thadeu Weber a filosofia hegeliana, de fato, tenta atrelar o reconhecimento à efetivação da liberdade, ou seja, a vontade livre. Isso significa que em Hegel a realização da vontade livre individual permeia o reconhecimento recíproco das vontades dos outros e das instituições sociais. É nessa perspectiva que o filósofo alemão constrói os argumentos para a Filosofia do Direito (1820). Cf. WEBER, T. Liberdade, direito e reconhecimento na Filosofia do Direito de Hegel, In: Revista de Estudos Constitucionais, Hermenêutica e Teoria do Direito, 2015, p. 297-30.

3 "As pessoas podem ter sua identidade definida em parte por seu compromisso moral ou espiritual [...]. Ou podem defini-la em parte pela nação ou tradição a que pertencem [...]" (TAYLOR, 1997, p. 44).

\begin{tabular}{|l|l|l|l|l|}
\hline Q Rovista Qialectus & Ano 5 & n. 12 & Janeiro - Julho 2018 & p. 400-418 \\
\hline
\end{tabular}


Assim, a presente exposição tem como meta, pretensão aproximar as posturas conceituais de Taylor e Honneth acerca da categoria reconhecimento. O fio condutor para tal empreitada será a filosofia hegeliana, pois ambos tentam reatualizar o pensamento do autor do século XIX a partir de novas premissas. Dentre elas, o aspecto da reconstrução do indivíduo na modernidade, self, (Taylor), ou ainda pelas experiências negativas de não reconhecimento (Honneth).

O texto como um todo irá se estruturar a partir dos seguintes tópicos: 1) a construção do reconhecimento dialogal em Taylor; 2) O papel do self; 3) A Influência dos escritos de Iena em Honneth 4) O Reconhecimento em Honneth em seus aspectos positivos e negativos.

Diante de tal divisão perceber-se-á a importância da presente discussão e as possíveis implicações que esse tema poderá gerar aos atores sociais (grupos, organizações, entidades) envolvidos no mundo atual.

\section{2- O Reconhecimento em Taylor enquanto Aspecto Identitário Dialogal}

Taylor busca conceber uma filosofia pautada pelo primado do reconhecimento. Porém, não qualquer tipo de reconhecimento feita às pressas, sem mediações com o real. Ao contrário, sua análise tem o objetivo de expressar as diferenças culturais, morais e comportamentais existentes entre os diferentes povos e nações. Essa proposta de análise ele o denomina de reconhecimento multicultural.

Para tanto, o autor canadense realiza um profundo estudo historiográfico da modernidade visando desvelar quais os fatores a tornaram possível. Neste empreendimento intelectual e filosófico, a política de reconhecimento emerge como uma das mais importantes contribuições do canadiano às demandas das políticas democráticas atuais.

Segundo Taylor, a exigência do reconhecimento na atualidade adquire certa premência devido à suposta relação entre reconhecimento e identidade. Neste último, a pessoa se define como ela é, ou seja, suas atitudes, características pessoais tornando-a diferente de outra pessoa. Em última instância, a identidade define a pessoa de o porquê dela pertencer a humanidade (TAYLOR, 1998, p.45). Neste contexto, os indivíduos e grupos não lutam apenas para obterem o reconhecimento de suas diferenças. As lutas

\begin{tabular}{|l|l|l|l|l|}
\hline Qevista Dialectus & Ano 5 & n. 12 & Janeiro - Julho 2018 & p. 400-418 \\
\hline
\end{tabular}


por reconhecimento se entrelaçam também com lutas pela distribuição tanto do poder político, quanto do bem-estar econômico.

Ora, na maior parte das sociedades contemporâneas como Canadá, Estados Unidos, Europa, América Latina - destacadamente o Brasil -, a fragmentação inerente ao multiculturalismo, caracterizadora de um pluralismo identitário, apresenta-se como uma questão marcante. Isso se deve ao surgimento de movimentos radicais que tentam eliminar as diversas formas de grupos sociais. Exemplos disso não faltam no mundo atual. Ações como o genocídio, discriminação racial e preconceito contra a orientação sexual de cada pessoa são alguns tipos de atitudes contra políticos, ou seja, manifestações que vão de encontro ao estabelecimento de uma cultura da tolerância, do respeito às diferenças. Tais atos são formas de solapar ou alijar as diferenças culturais presentes na dinâmica das sociedades. Com efeito, tentam implantar um "ideal de homogeneidade", baseado no controle e passividade que são próprios das políticas de massificação e totalitarismo que emergiram no século XX.

Contudo, ainda no século XX, esta condição passa a ser questionada mediante a eclosão de uma forte exaltação da heterogeneidade, das diferenças existentes nos grupos sociais. Neste sentido, a política do reconhecimento de Taylor surge como uma luta pela reconstrução pessoal e pelo resgate identitário - dos grupos, das minorias étnicas e das comunidades oprimidas, por seus mais diversos motivos - em face da dinâmica do multiculturalismo. Mesmo assim, Taylor admite a falta deste termo na sociedade atual. Mesmo porque os indivíduos não têm identidade própria pelo fato dos mesmos não se sentirem pertencidos às diversas formas de instituição (Estados, famílias etc.).

A formação da identidade de um povo ou de um indivíduo possui diversas influências. O próprio autor canadense admite essa possibilidade ao falar que:

A identidade é formada em parte, pela existência ou inexistência de reconhecimento e, muitas vezes, pelo reconhecimento incorreto dos outros, podendo uma pessoa ou grupo de pessoas serem realmente prejudicadas, serem alvo de uma verdadeira distorção, se aqueles que os rodeiam refletirem uma imagem limitada, de inferioridade ou de desprezo por eles mesmos (TAYLOR, 1998, p. 45).

Por isso o filósofo canadense argumenta que o não reconhecimento ou o reconhecimento incorreto pode afetar negativamente o indivíduo. Essa negatividade é constituída de diversas formas. Seja uma agressão física ou não (psicológica, verbal), a

\begin{tabular}{|l|l|l|l|l|}
\hline Q Povista Dialectus & Ano 5 & n. 12 & Janeiro - Julho 2018 & p. 400-418 \\
\hline
\end{tabular}


pessoa pode se sentir constrangida nas suas potencialidades. Dessa forma, Taylor demonstra que a centralidade da questão do reconhecimento, assim como a necessidade de sua emergência nos diferentes espaços públicos da vida cotidiana dos agentes sociais, é de crucial importância. Importância essa que não limita ao campo das ciências ou mesmo da filosofia política contemporânea.

$\mathrm{O}$ ato de reconhecer atinge, na verdade, as ações políticas concretas dos municípios, estados, nações e agências internacionais, visto que os danos causados pelo não reconhecimento podem ser catastróficos para inúmeras pessoas, grupos e civilizações. Nesse sentido, a falta de reconhecimento gera a falta do respeito, da tolerância ao outro. Sem falar ainda que pode "marcar as suas vítimas de forma cruel, subjugando-as através de um sentimento incapacitante de ódio contra elas mesmas. Por isso, o respeito devido não é um ato de gentileza para com os outros. É uma necessidade humana vital"' (TAYLOR, 1998, p.46).

Não por acaso a relevância do conceito de self no autor canadense. Isso porque Taylor está preocupado com os processos de construção do self ${ }^{4}$ ao defender que os indivíduos dependem do reconhecimento intersubjetivo para se auto realizarem. E para isso, ele apresenta a sua definição de multiculturalismo. Porém, o termo é carregado de simbologia, visto que alguns autores não possuem consenso acerca de sua definição.

Em linhas gerais, adotar o princípio multicultural se refere às estratégias e políticas adotadas para governar ou administrar problemas de diversidade e de multiplicidade gerado pelas sociedades multiculturais. Para Weller ${ }^{5}$, o ismo do termo em questão tende a converter o multiculturalismo em uma doutrina filosófica, reduzindo-o a uma singularidade formal e fixando-a numa condição petrificada. $O$ termo multiculturalismo descreve uma série de processos e estratégias sempre inacabados e assim como existem distintas sociedades multiculturais, também podemos constatar distintos multiculturalismos e distintas correntes teóricas discutindo os distintos multiculturalismos.

4 A Obra As fontes do self representa a análise de Taylor de como a era moderna construiu o termo reconhecimento. Nela, o autor faz uma espécie de "genealogia filosófica" de como o self foi construído nas múltiplas facetas de nossa sociedade. Ele perpassa por categorias como a racionalidade, a autonomia, a interioridade e a autenticidade, que foram construídas filosófica e praticamente ao longo dos séculos.

5 Para aprofundar no debate acerca das várias definições de multiculturalismo, cf. WELLER, Wivian. Questões filosóficas contemporâneas em educação: multiculturalismo e políticas da diferença. 2010.

\begin{tabular}{|l|l|l|l|l|}
\hline Ronista Dialectus & Ano 5 & n. 12 & Janeiro - Julho 2018 & p. 400-418
\end{tabular}


Duarte \& Smith $^{6}$ apontam ainda uma distinção entre condição multicultural e multiculturalismo. A expressão condição multicultural descreve a presença demográfica de diferentes grupos étnicos dentro de uma população, relacionando fatores adjacentes às experiências históricas de grupos específicos, crenças culturais, valores dentro da sociedade geral. Por contraste, a expressão multiculturalismo tem a ver com a forma como um indivíduo interpreta ou vê o mundo e percebe o seu lugar nele - sendo o mundo esse lugar caracterizado pela condição multicultural. Com efeito, o multiculturalismo tem a ver com a forma como um indivíduo avalia esse sentido de espaço para si próprio e para o outro e como que se propõe a fazer em resposta à condição multicultural.

Como se pode observar, há diversas leituras e interpretações ${ }^{7}$ para o termo. Em Taylor, o tema multiculturalismo possui outro contexto, bem definido: se expressa em caráter normativo dialogal. Dito de outro modo, sua teoria se apresenta como proposta de solução para os problemas provenientes da convivência entre as pessoas e os diferentes grupos culturais que buscam na coexistência conjunta, manter suas pautas culturais e sociais. E será neste contexto macro de discussão que o autor canadense chama atenção para o aspecto político do multiculturalismo.

Taylor parte para a defesa do contexto multicultural associado à necessidade de uma política legítima de reconhecimento público das diferenças, por parte das instituições públicas. Este objetivo justificaria a defesa da sobrevivência das comunidades culturais presentes nas sociedades multiculturais por estarem vinculadas à formação das identidades humanas. Sem falar ainda que tais comunidades identitárias teriam ainda acesso à concessão de direitos especiais aos grupos culturais específicos.

Ora, faz-se necessário essa defesa do aspecto multicultural da política intersubjetiva. A peculiaridade da modernidade focada por Taylor reside no que ele identifica em termos de virada em direção à interioridade, que implica, por parte do sujeito, a aquisição de uma inédita centralidade em relação às épocas anteriores,

\footnotetext{
6 A discussão acerca de como o termo pode ser aplicado nas suas mais diversas facetas não é consenso entre os comentadores. O exemplo disso, encontra-se neste escrito dos dois autores. Cf. DUARTE, Eduardo Manuel; SMITH, Stacy. Introduction: "Multicultural Education - What For?" In: (Orgs.): Foundational perspectives in multicultural education. United States, Allyn \& Bacon, 1999.

7 Cámara em seu livro Integración o Multiculturalismo, Persona y Derecho, Navarra: Universidad de Navarra, 2003, p.163-183, destaca também duas outras possíveis interpretações ao termo: enquanto fato social e enquanto teoria. No primeiro modelo, o multiculturalismo diz respeito à convivência de grupos distintos culturalmente num mesmo espaço territorial tanto no nível dos Estados nacionais como no nível global. Já no segundo modelo, apresenta como proposta mediadora dos conflitos ora individuais, ora coletivos. E será neste ponto que Taylor percebe relevância ao termo.
}

\begin{tabular}{|l|l|l|l|l|}
\hline Q Rovista Dialectus & Ano 5 & n. 12 & Janeiro - Julho 2018 & p. 400-418 \\
\hline
\end{tabular}


especialmente no que tange à moralidade. Trata-se de um processo gradativo que tem levado à autonomização ética do agente, ou seja, à consciência de que as motivações devem ser buscadas na profundidade do próprio indivíduo.

À luz do que precede, pode-se afirmar que Taylor identifica um aspecto crucial da cultura moderna, que é a liberdade enquanto valor: ela se torna a categoria explicativa dos demais fins contemplados pela reflexão ética. Diante disto, subjaz uma noção de cidadania que prima pelo bem-estar dos diferentes grupos. Mas, para que isso ocorra se faz necessário que aconteça algumas condições essenciais: a garantia dos direitos fundamentais, o entendimento das particularidades de cada povo, o limite territorial e a soberania do Estado. Sem esquecer, logicamente, que tais condições se efetivem em preceitos ideológicos aceitáveis, ou seja, respeitando-se às diversas opiniões. Somados todos esses aspectos, uma política multicultural aparece.

\section{3- A Decadência do Sujeito moral através do Self em Charles Taylor.}

A obra de Taylor se destaca na recuperação do debate atual acerca da efetividade de um bem comum a partir das referências de uma política governamental de inserção das minorias. Esse bem comum é pensado a nível coletivo, ou seja, para todos em sociedade. Em Taylor, porém, tal postura coletiva pode ser pensada ao aspecto cultural de outros povos: o multiculturalismo. Mesmo assim, o sujeito na sua individualidade não pode ser esquecido. Mesmo porque ele possui particularidades que diferem de uma sociedade, de uma cultura. A inserção da noção de indivíduo, contudo, não pode cair no erro das posturas modernas da tradição que isolaram o homem em seu aspecto individualista, atomizada.

O filósofo canadense destaca o efeito do autocentramento na instrumentalização do mundo. Em outras palavras, uma postura em que o sujeito confere caráter utilitário a todas as associações a que pertence. A consequência nociva a esse aspecto é que o indivíduo não obtém reconhecimento algum por possíveis demandas a seu self. A escolha de um modo de vida deve efetivar-se a partir de um monólogo crucial. E qual é este ponto? O indivíduo indo se reencontrar consigo mesmo, encontrando o que lhe é original. Após a essa condição, o homem poderá buscar sua própria expressão vital. Para Taylor, esse tipo de existência, característico de um antropocentrismo radical, questiona a própria atribuição de sentido para a vida. Tal

\begin{tabular}{|l|l|l|l|l|}
\hline Q Ronista Qialectus & Ano 5 & n. 12 & Janeiro - Julho 2018 & p. 400-418 \\
\hline
\end{tabular}


questionamento leva o sujeito simplesmente a espelhar nem mesmo a natureza que está a sua volta. A resultante de toda essa situação, nesse sentido, não poderia ser mais empobrecedora: o surgimento do narcisismo.

Taylor sustenta que o narcisismo, particularmente em sociedades dominadas pela relação de mercado e pela burocracia, só pode redundar no enfraquecimento dos regimes democráticos (TAYLOR, 2000, p. 112). Um "eu” desengajado equivale a um sujeito inteiramente desinteressado de sua posição no espaço público. Acrescentando-se a essa autopercepção o elevado custo de organizar um grupo, o mais provável é que as pessoas desistam de atuar politicamente. Seja por motivos pessoais ou pelas contingências externas ao grupo. Já aquelas que conseguem se associar encontrem enormes desafios para mobilizar maiorias significativas em torno de programas e políticas de interesse comum.

$\mathrm{O}$ autor admite a possibilidade de que a disseminação da linguagem dos direitos aponta para uma saída deste tipo de impasse. Ainda assim, mesmo que os direitos individuais sejam enfatizados, é a fragmentação dos interesses que recebe a maior força propulsiva. Para sair desse impasse, o autor propõe a noção de self. Na modernidade, o indivíduo encontra sua referência no próprio self (nele mesmo), tornando-se independente das redes de interlocução que o formam ou, pelo menos, relativizando-as.

A instrumentalização do mundo e a busca de um sentido para a existência no interior de si próprio seriam então os fatores responsáveis por este mal-estar. Permeada por ideais e interdições, esta identidade, em permanente busca de sentido para sua existência, efetivaria forte conexão entre selfhood (individualidade) e o "bem". Definindo o que é bom como aquilo que cada um de nós, com nossos recursos e a nosso modo, diz que é, a tolerância, transmudada em relativismo, passa a ocupar o lugar de proeminência no espaço ético.

A esse estado de coisas, porém, Taylor acrescenta o reconhecimento da vivência de uma "ética da autenticidade". Segundo o autor, ela permeia a maneira como nos concebemos, envolvendo forte recomendação do exercício de nossa liberdade na constituição de nosso modo de viver. E é aqui que a leitura de Taylor começa a se distanciar de alguns autores.

\begin{tabular}{|l|l|l|l|l|}
\hline Q Povista Dialectus & Ano 5 & n. 12 & Janeiro - Julho 2018 & p. 400-418 \\
\hline
\end{tabular}


O primeiro deles é Sennett, $(1943-)^{8}$ para quem a autenticidade não é outra coisa senão o nome contemporâneo do ethos puritano destituído de qualquer referência transcendental e, portanto, com efeito, puramente corrosivo sobre a tessitura social. $\mathrm{O}$ segundo é Georg Simmel $^{9}$ (1858-1918) para quem a autenticidade corresponde a uma busca de singularidade capaz de tornar cada indivíduo insubstituível na trama social.

Para Taylor, no entanto, e aqui motivado pelo texto de Trilling ${ }^{10}$, a tensão ou mal-estar derivam precisamente do conflito que a busca da autenticidade produz sobre a representação narcísica do "eu". O autor argumenta ainda que a busca da autorrealização é genuína, no sentido de a pessoa acreditar que deve construir a seu modo sua vida, sob pena de desperdiçá-la (TAYLOR, 2000b, p.17). Em vez de limitarse, como faz Trilling, ao registro desse desejo, que se expressa no relativismo próprio ao "cada um na sua", Taylor criticará a base ética que legitima tal anseio.

Sugere ainda que esse ideal de autenticidade, próprio à formulação moderna do conceito de identidade, torna particularmente complicada a conexão presumida entre identidade e reconhecimento. Em suma, o debate acerca da identidade individualizada não propiciou resultados consistentes, plausíveis na modernidade. Isso porque se o indivíduo autêntico é aquele que busca em si mesmo, em sua maneira particular de ser, a sua verdade, quem deverá ou poderá reconhecê-lo como tal? (TAYLOR, 1995, p.227).

Emerge com essa pergunta uma outra, ainda mais inquietante: quem pode me assegurar que de fato estou em contato com meu sentimento, atingindo meu “interior mais profundo"? Este monólogo, na perspectiva de Taylor, não tem ponto de chegada porque seu início é equivocado, isto é, parte da presunção de uma "geração interna do eu". Apontando para a desconsideração da relevância do diálogo na produção da identidade, Taylor contra-argumenta que, se a busca da autenticidade envolve criatividade, originalidade e, provavelmente, oposição a regras, ela não se esgota neste movimento.

A autenticidade requer, também, abertura para um horizonte de significados. Esse horizonte, nesse sentido, ganha uma relevância neste contexto na medida em que o

8 Para mais detalhes acerca do pensamento de Richard Senneth, c.f A queda do homem público. Rio de Janeiro, Zahar, 1986.

9 Para mais detalhes acerca do pensamento de Georg Simmel, c.f VANDEBERGUE, Frédéric. As sociologias de Georg Simmel. Bauru: Edusc, 2005 e c.f WAIZBORT, Leopold. As aventuras de Georg Simmel. São Paulo: Edusp, 2004.

10 Acerca deste autor, a obra Sincerity and authenticity (1974) se destaca pela influência decisiva no pensamento de Taylor acerca da construção do conceito de self.

\begin{tabular}{|c|c|c|c|c|}
\hline Rovista Dialectus & Ano 5 & n. 12 & Janeiro - Julho 2018 & p. $400-418$ \\
\hline
\end{tabular}


caminho a ser implantado por essa abertura ${ }^{11}$ é o reconhecimento dialogal, ou seja, que envolva a intersubjetividade. Mesmo que o indivíduo se sinta solitário em um mundo cada vez mais fragmentado, fragilizado nos relacionamentos sociais o ato de reconhecer é imperativo nessa mudança.

Até porque quando se conceitua o ato de reconhecer em contraposição ao modelo individual da modernidade, fica clara a busca de autenticidade. Em consequência, produz conflito internamente ao indivíduo uma autocrítica na representação narcísica do "eu". Em outras palavras, o desejo de autorrealização que desconsidere as demandas postas por nossas relações com outras pessoas ou por fatores distintos de nossas aspirações necessariamente será frustrado (TAYLOR, 2000, p. 35 e p.66).

Percebe-se, portanto, que Taylor não dá uma resposta definitiva ao tema do Reconhecimento. O filósofo alemão Axel Honneth tentará a seu modo expressar a filosofia do reconhecimento. Mais especificamente, a partir de sua releitura aos escritos juvenis de Hegel no período de Iena.

\section{4- O Reconhecimento em Honneth em seus Aspectos Positivos e Negativos.}

Buscando construir uma teoria social de caráter normativo, Honneth parte da proposição de que o conflito é intrínseco tanto à formação da intersubjetividade como dos próprios sujeitos. Ele destaca que tal conflito não é conduzido apenas pela lógica da autoconservação dos indivíduos, como pensavam Maquiavel e Hobbes, por exemplo. Trata-se, sobretudo, de uma luta moral, visto que a organização da sociedade é pautada por obrigações intersubjetivas. ${ }^{12}$ Nesse sentido, o autor adota a premissa de Hegel, para quem a luta dos sujeitos pelo reconhecimento recíproco de suas identidades gera "uma pressão intrassocial para o estabelecimento prático e político das instituições garantidoras de liberdade." (HONNETH, 2003, p. 29).

A ideia hegeliana é a de que os indivíduos se inserem em diversos embates através dos quais não apenas constroem uma imagem coerente de si mesmos, mas

11 José Souza em Uma teoria crítica do reconhecimento defende a possibilidade de uma abertura de horizontes. No lugar de uma perspectiva multicultural, intersubjetiva, Souza postula que a autenticidade é uma forma expressiva de relacionamento entre duas ou mais pessoas. Isso porque o caminho para se atingir um engajamento político é muito maior se comparado ao isolamento. Para mais detalhes, c.f SOUZA, J. Uma teoria crítica do reconhecimento, Lua Nova, N.50 p.133-158.

12 Charles Taylor, defende a tese de que a luta por reconhecimento não é algo apenas moral, normativo; "é uma necessidade humana vital" (TAYLOR, 1994, p. 26).

\begin{tabular}{|c|c|c|c|c|}
\hline Qovista Dialectus & Ano 5 & n. 12 & Janeiro - Julho 2018 & p. $400-418$ \\
\hline
\end{tabular}


também possibilitam a instauração de um processo em que as relações éticas da sociedade seriam liberadas de unilaterizações e particularismos. Esses embates dar-seiam, na visão de Hegel, nos âmbitos da 1) família; 2) direito (identificado com a sociedade civil) e 3) Eticidade (representada pelo Estado, que é definido por Hegel como o espírito do povo).

Honneth atualiza o termo reconhecimento, utilizado pelo jovem Hegel nos escritos de Jena, por meio da psicologia social de Georg H. Mead ${ }^{13}$ (1863-1931). Assim como Hegel, o psicólogo norte-americano defende a gênese social da identidade e vê a evolução moral da sociedade na luta por reconhecimento. Mead aprofunda o olhar intersubjetivista, defendendo a existência de um diálogo interno (ora entre impulsos individuais, ora pela cultura internalizada), e investiga a importância das normas morais nas relações humanas. De acordo com ele, nas interações sociais, ocorrem conflitos entre o "eu" e a "cultura" e os "outros", por meio dos quais indivíduos e sociedade desenvolver-se-iam normalmente.

Mead defende a ideia, semelhante ao que Honneth desenvolve em sua teoria crí- tica, que o reconhecimento passa por três tipos de relação: as primárias (guiadas pelo amor), as jurídicas (pautadas por leis) e a esfera do trabalho (na qual os indivíduos poderiam mostrar-se valiosos para a coletividade). A partir desse insight, Honneth sistematiza uma teoria do reconhecimento.

São as lutas moralmente motivadas de grupos sociais, sua tentativa de estabelecer institucional e culturalmente formas ampliadas de reconhecimento recíproco, aquilo por meio do qual vem a se realizar a transformação normativamente gerida das sociedades. (HONNETH, 2003, p. 156).

Ele atualiza os argumentos de Hegel e de Mead, extraindo deles três princípios integradores: as ligações emotivas fortes; a adjudicação de direitos e a orientação por valores.

As primeiras se concretizam por meio das relações de amor e seriam as mais fundamentais para a estruturação da personalidade dos sujeitos. Apoiando-se na psicanálise de Donald Winnicott ${ }^{14}$ (1896-1971), Honneth analisa as relações entre mãe e

13 A fim de conhecer o pensamento deste intelectual norte-americano, vide Diálogo com os tempos moderno: o pensamento social e político de G. H. Mead. Rio de Janeiro: Tempo Brasileiro, 2009. A referida obra foi escrita por Filipe Carreira da Silva.

14 A respeito da psicanálise em Donald Winnicott, Honneth aponta dois livros como fundamentais sobre o assunto. Da pediatria à psicanálise. Tradução de Davy Litman Bogomoletz. Rio de Janeiro: Imago,

\begin{tabular}{|l|l|l|l|l|}
\hline Revista Qialectus & Ano 5 & n. 12 & Janeiro - Julho 2018 & p. 400-418 \\
\hline
\end{tabular}


filho, indicando que elas passam por uma transformação que vai da fusão completa à dependência relativa. Nessa dinâmica conflitiva, um aprende com o outro a se diferenciarem e verem-se como autônomos: ainda que dependentes eles podem sobreviver sozinhos. Disso advém a possibilidade da autoconfiança. Para Honneth, em cada relação amorosa se atualiza o jogo dependência/autonomia oriundo dessa fusão originária, dele dependendo a confiança básica do sujeito em si mesmo e no mundo.

As relações de direito, por sua vez, pautam-se pelos princípios morais universalistas construídos na modernidade. O sistema jurídico deve expressar interesses universalizáveis de todos os membros da sociedade, não admitindo privilégios e gradações. Por meio do direito, os sujeitos reconhecem-se reciprocamente como seres humanos dotados de igualdade, que partilham as propriedades para a participação em uma formação discursiva da vontade. As relações jurídicas geram auto-respeito: "consciência de poder se respeitar a si próprio, porque ele merece o respeito de todos os outros" (HONNETH, 2003, p. 195). Honneth assinala que o que caracteriza essa igualdade é algo construído historicamente, sendo que a modernidade é marcada pela extensão dos atributos universais. Recorrendo às clássicas proposições de T.H Marshall (1893-1981), o autor demonstra as lutas por reconhecimento travadas para a construção dos direitos civis, políticos e sociais, todos voltados para a configuração de cidadãos com igual valor.

A terceira e última dimensão do reconhecimento dá-se no domínio das relações de solidariedade, que propiciam algo além de um respeito universal. Sobre o assunto, Honneth afirma o seguinte:

\footnotetext{
Para poderem chegar a uma autorrelação infrangível, os sujeitos humanos precisam, além da experiência da dedicação afetiva e do reconhecimento jurídico, de uma estima social que lhes permita referir-se positivamente a suas propriedades e capacidades concretas. (HONNETH, 2003, p. 198).
}

Para o autor, é no interior de uma comunidade de valores, com seus quadros partilhados de significação, que os sujeitos podem encontrar a valorização de suas idiossincrasias. E vários conflitos buscam, exatamente, a reconfiguração de tais quadros dada a revisibilidade destes.

2000 e A família e o desenvolvimento individual. Tradução de Marcelo Brandão Cipola. São Paulo: Martins Fontes, 1983.

\begin{tabular}{|c|c|c|c|c|}
\hline Qovita Dialectus & Ano 5 & n. 12 & Janeiro - Julho 2018 & p. $400-418$ \\
\hline
\end{tabular}


Nas sociedades modernas, as relações de estima social estão sujeitas a uma luta permanente na qual os diversos grupos procuram elevar, com os meios da força simbólica e em referência às finalidades gerais, o valor das capacidades associadas à sua forma de vida. (HONNETH, 2003, p. 207).

Aos três reinos do reconhecimento, Honneth associa, respectivamente, três formas de desrespeito: 1) Aquelas que afetam a integridade corporal dos sujeitos e, assim, sua autoconfiança básica; 2) A denegação de direitos, que destrói a possibilidade do autorrespeito, à medida que inflige ao sujeito o sentimento de não possuir o status de igualdade e, 3) A referência negativa ao valor de certos indivíduos e grupos, que afeta a autoestima dos sujeitos.

O filósofo do reconhecimento acredita que todas essas formas de desrespeito e degradação impedem a realização do indivíduo em sua integridade, totalidade. Mas, se por um lado, o rebaixamento e a humilhação ameaçam identidades, por outro, eles estão na própria base da constituição de lutas por reconhecimento. O desrespeito pode tornar-se impulso motivacional para lutas sociais, à medida que torna evidente que outros atores sociais impedem a realização daquilo que se entende por bem viver.

Esse é o ponto defendido por Honneth, quando, recorrendo a Dewey, ele afirma que os obstáculos, que surgem ao longo das atividades dos sujeitos, podem se converter em indignação e sentimentos negativos (vergonha, ira). Tais sentimentos permitiriam a um deslocamento da atenção dos atores para a própria ação, para o contexto em que ela ocorre e para as expectativas ali presentes. Disso poderiam advir impulsos para um conflito, desde que o ambiente político e cultural fosse propício para tanto. Nesse ponto, a ideia é que:

Toda reação emocional negativa que vai de par com a experiência de um desrespeito de pretensões de reconhecimento contém novamente em si a possibilidade de que a injustiça infligida ao sujeito se lhe revele em termos cognitivos e se torne o motivo da resistência política. (HONNETH, 2003, p. 224).

O que o autor alemão defende, em última instância, é que os conflitos intersubjetivos por reconhecimento, encetados por situações desrespeitosas vivenciadas cotidianamente, são fundamentais para o desenvolvimento moral da sociedade e dos indivíduos. Esta é à base de sua concepção formal de boa vida, a qual "tem de conter todos os pressupostos intersubjetivos que hoje precisam estar preenchidos para que os

\begin{tabular}{|l|l|l|l|l|}
\hline Qevista Dialectus & Ano 5 & n. 12 & Janeiro - Julho 2018 & p. 400-418 \\
\hline
\end{tabular}


sujeitos se possam saber protegidos nas condições de sua autorrealização" (HONNETH, 2003, p.270). Tal eticidade formal - alicerçada no amor, no direito e na estima social só pode ser construída na interação social. E é a partir desta sistematização que Honneth propõe sua teoria crítica para a categoria reconhecimento.

A partir dos argumentos de Hegel e de Mead, Honneth fundamenta seu argumento. Mas, de que modo Honneth atualiza o pensamento hegeliano? A partir do confronto dos escritos juvenis de Hegel em Jena na contemporaneidade.

\section{5- A Filosofia do Reconhecimento dos Escritos Juvenis de Hegel na Perspectiva Crítica em Honneth}

O objetivo hegeliano, no que tange à fundamentação da noção de vida ética, é desvendar o modo pelo qual a natureza ética alcança seu verdadeiro direito. Neste ponto, Honneth concorda com Hegel. Porém, a questão vai mais além: o que acontece com a ocorrência de negações subjetivas, que se repetem diuturnamente, provocando a independência das relações éticas? De acordo com Hegel, a unilaterização e a particularização da natureza humana limitam o processo especulativo da ideia de liberdade na vida ética. É pela diferença que a eticidade natural pode desdobrar-se e atingir estágios sucessivos de desenvolvimento ético, até o estado de unidade que reúne o universal e o particular.

Esse vir-a-ser da eticidade pode ser entendido em Hegel, segundo Honneth, como um processo de universalização conflituosa dos potenciais morais contidos na eticidade natural, assim como uma superação gradual do negativo ou do subjetivo (HONNETH, 2003, p. 44). Contudo, é somente após os primeiros anos em Jena, depois dos quais Hegel reconsidera o pensamento de Fichte - principalmente no seu texto Fundamento do Direito Natural. ${ }^{15}$ No Sistema da vida ética, publicado em 1802, Hegel realmente pode explicitar, de forma sistemática, sua compreensão do vir-a-ser como um reconhecimento intersubjetivo da particularidade de todos os indivíduos. Esse ponto, Honneth concorda que sua teoria é extraída do raciocínio hegeliano.

\footnotetext{
15 Nesta obra, Fichte havia classificado o reconhecimento como ação recíproca entre os indivíduos anterior à relação jurídica. Hegel, além de classificá-lo meramente como forma de eticidade natural humana, agora o coloca inserido nas formas comunicativas de vida. Em outras palavras, modos de uma intersubjetividade prática pela qual os indivíduos se contrapõem entre si num movimento que é direcionado pelo reconhecimento.
}

\begin{tabular}{|l|l|l|l|l|}
\hline Gevista Qialectus & Ano 5 & n. 12 & Janeiro - Julho 2018 & p. 400-418 \\
\hline
\end{tabular}


Não por acaso que o conceito inovador de social construído por Hegel, ao longo de seus escritos em Jena, gera uma dinamização extremamente profícua. No entender de Honneth, abrange não só o domínio de tensão moral - marcadamente conflituoso - mas também o médium social pelo qual os conflitos se resolvem, proporcionando o movimento ético da luta social. Mesmo assim, Honneth critica vários pontos da teoria hegeliana do reconhecimento.

Primeiramente, o enfoque dado por Hegel no Sistema da vida ética para o movimento das relações humanas interativas. Tal movimento perde um pouco seu espaço quando o filósofo parte para uma teoria da consciência. Segundo Honneth, as análises feitas pelo filósofo da eticidade vão, aos poucos, transferindo-se das formas de interação social e das relações éticas para uma análise das etapas de construção da consciência individual. Essa mudança acarreta o seguinte: não mais conceber as relações comunicativas como algo anterior aos indivíduos e não mais como agente mediador da consciência individual; mas apenas como mediador do processo de universalização social.

Hegel pagou caro o ganho teórico de sua virada para a filosofia da consciência com a renúncia a um intersubjetivismo forte. A virada para a filosofia da consciência faz com que ele perca de vista a ideia de uma intersubjetividade prévia do ser humano em geral e lhe obstrui o caminho para uma solução inteiramente diferente, que teria consistido em realizar a distinção necessária de diversos graus de autonomia pessoal dentro do próprio quadro da teoria da intersubjetividade. (HONNETH, 2003, p.66).

Além de criticar alguns pontos do Sistema da vida ética, o filósofo do reconhecimento aponta alguns contrassensos de outra obra do jovem Hegel de Jena: Realphilosophie - ou Filosofia do Real - de 1805/1806. Honneth considera que Hegel, ao se utilizar de conceitos como espírito subjetivo e espírito objetivo, procurou evidenciar etapas pelas quais se desdobra novas formas de reconhecimento. Na primeira, por meio do desenrolar da relação amorosa; e na segunda, por meio de uma constituição conflituosa da relação jurídica. O que Honneth entende como implicação desta tentativa é que Hegel não consegue suprir as expectativas criadas por ele mesmo, pois já não pode mais pensar numa Eticidade social do Estado como uma relação constituída e concretizada intersubjetivamente.

Se Hegel tentasse dar conta das expectativas assim sugeridas, ele teria de conceber a esfera ética do Estado como uma relação intersubjetiva na qual os

\begin{tabular}{|l|l|l|l|l|}
\hline Revista Qialectus & Ano 5 & n. 12 & Janeiro - Julho 2018 & p. 400-418 \\
\hline
\end{tabular}


membros da sociedade podem saber-se reconciliados uns com os outros justamente sob a medida de um reconhecimento recíproco de sua unicidade o respeito de cada pessoa pela particularidade biográfica do outro formaria de certo modo o fermento habitual dos costumes coletivos de uma sociedade. (HONNETH, 2003, p.107-108).

Os hábitos culturais dos membros de uma sociedade garantem a integração social da coletividade na medida em que expressam a unidade e unicidade da mesma. De acordo com a proposta de reconhecimento honnetiano, tal unidade é o produto daquela eticidade, distinguindo daí diferentes formas de interação social. "Esse passo, porém, a guinada consequente para um conceito de eticidade próprio de uma teoria do reconhecimento, Hegel não efetuou." (HONNETH, 2003, p.113). Segundo Honneth, Hegel finaliza seu texto praticamente anulando essa possibilidade, pois, sendo o Estado a concreção institucional daquela experiência de auto-reflexão do espírito, as relações interativas entre os sujeitos na sociedade ficam subjugadas às relações destes para com a instância superior do Estado. Nele, a vontade geral se torna a instância de poder único, referente aos sujeitos de direito e representante de sua qualidade espiritual.

Em decorrência, a eticidade, assim descrita por Honneth, constitui-se na relação dos sujeitos com o Estado apenas, e não nas relações entre si. Além disso, revela ainda o caráter autoritário dos hábitos culturais que potencialmente devem se desenvolver a partir do estabelecimento desta relação como a relação ética por excelência. Honneth afirma ainda que a única forma de Hegel conceber a fundação do Estado, colocado pelo filósofo alemão na Realphilosophie, é tê-la como resultado do poder tirânico de "grandes homens", personalidades fortes que expressam a vontade absoluta.

Para Honneth, portanto, falta à Realphilosophie um conceito intersubjetivo de "eticidade", no que se refere ao reconhecimento solidário da singularidade individual, para que possa cumprir as suas próprias exigências.

Hegel pode expor em sua Realphilosophie a construção do mundo social como um processo de aprendizagem ético que conduz, passando por diversas etapas de uma luta, a relações cada vez mais exigentes de reconhecimento recíproco. Se ele tivesse seguido o mesmo processo de modo coerente até a constituição da comunidade ética, então lhe teria ficado patente também a forma de uma interação social na qual cada pessoa pode contar, para sua particularidade individual com um sentimento de reconhecimento solidário. (HONNETH, 2003, p. 113). 
Não é à toa que esse escrito de 1805/1806 foi o último texto que tratou do reconhecimento enquanto categoria ética, política. Já na Fenomenologia do Espírito de 1807, Hegel dá outra conotação a categoria reconhecimento: o papel de formar a autoconsciência. Mesmo assim, Honneth reconhece a importância de Hegel na construção de sua teoria crítica. O que aproxima os dois filósofos é o papel da intersubjetividade para o processo de mediação, efetivação do reconhecimento. É nela que ocorre uma interação especulativa, conceitual entre os sujeitos. Portanto, a filosofia juvenil de Hegel influência de forma decisiva a teoria crítica de Axel Honneth.

\section{Conclusão}

A política de identidade e o conceito de reconhecimento têm se transformado em questões dominantes da teoria política contemporânea. Como conceito, o reconhecimento significa que um indivíduo ou grupo social reivindica o direito a ter sua identidade reconhecida, de forma direta ou através da mediação de um conjunto de instituições. As teorias que tem problematizado estas questões abordam tanto temas teóricos importantes como questões políticas centrais do nosso tempo, como a definição de direitos das minorias, reivindicações de autodeterminação nacional ou os desafios colocados por nossas sociedades cada dia mais multiculturais. Nesse sentido, Charles Taylor e Axel Honneth possuem visões interessantes do assunto.

A própria ideia de dignidade do cidadão e de reconhecimento universal representa, para Taylor, um dos pontos de início da elaboração moderna da noção de autenticidade. A individuação histórica de tal matriz teórica lhe é funcional à explicação do interesse da contemporaneidade pela política do reconhecimento. De fato, a nossa familiaridade com o discurso sobre o reconhecimento dá-se tanto na esfera íntima, onde a formação da identidade e do si é entendida como diálogo e luta ininterrupta, quanto na esfera pública, em cujo seio a política do igual reconhecimento tem chegado a exercer uma função cada vez mais importante.

Axel Honneth, por outro lado, reconhece a profundidade e fecundidade do projeto hegeliano de construção da teoria da intersubjetividade e também seus conceitos de reconhecimento e eticidade. Porém, não concorda com os rumos tomados pela filosofia de Hegel quando assume um modelo de filosofia da consciência na

\begin{tabular}{|l|l|l|l|l|}
\hline Q Povista Dialectus & Ano 5 & n. 12 & Janeiro - Julho 2018 & p. 400-418 \\
\hline
\end{tabular}


Fenomenologia do Espírito. A crítica de Honneth procura evidenciar tais contradições, mostrando que ele se coloca simpático ao projeto, mas crítico quanto à realização.

\section{REFERÊNCIAS}

ARAÚJO NETO, J.A.C. A categoria reconhecimento em Axel Honneth. In: Argumentos. Ano:3, n.5, 2011, p. 139-147.

BAVAGNANI, H.B. Luta por reconhecimento: a filosofia social do jovem Hegel segundo Honneth. Kinesis, v.1, n.1, mar. 2009, p.39-57.

BRANDÃO, M.G. Hegel: o estado como realização histórica da liberdade. In: WELLFORT, F. C. (Org.). Os clássicos da política. São Paulo: Ática, 2006. 11. ed.

FRASER, N. From distribution to recognition? dilemmas of justice in a 'postsocialist' Age. In:__ Justice Interruptus - critical reflections on the 'postsocialist' condition. London: Routledge, 1997.

HEGEL, G.W.F. O sistema da vida ética. Tradução de Artur Morão. Lisboa: Edições 70, 1991.

Sobre as maneiras científicas de tratar o direito natural. Tradução de Agemir Bavaresco e Sérgio B.Christino. São Paulo: Loyola, 2007.

HOBBES, T. Leviatã ou matéria, forma e poder de um Estado eclesiástico e civil. Tradução de João Paulo Monteiro e Maria Nizza da Silva. São Paulo: Abril Cultural, 1974. (Coleção Os Pensadores, XVI).

FRASER, N; HONNETH, A. Reditribution or recognition?: a political philosophical exchange. London: Verso, 2003.

FRASER, N. Recognition without ethics? Theory, Culture \& Society. Londres/New Delhi, Thousand Oaks, v. 18, n. 2-3, p. 21-42, 2001.

HONNETH, A. Luta por reconhecimento: a gramática moral dos conflitos sociais. Tradução de Luis Repa. São Paulo: Ed.34, 2003.

Patologias da Liberdade individual. O diagnóstico hegeliano da época e o presente. Tradução Luis Repa. Novos Estudos CEBRAP, n. 66 jul/2003, p. 77-90.

MATTOS, P. A Sociologia política do reconhecimento: as contribuições de Charles Taylor, Axel Honneth e Nancy Fraser. São Paulo: Annablumme, 2006.

\begin{tabular}{|c|c|c|c|c|}
\hline Ronita Oialeatus & Ano 5 & n. 12 & Janeiro - Julho 2018 & p. $400-418$ \\
\hline
\end{tabular}


MEAD, Georg H. Espiritu, persona y sociedad. México: Paidós, 1983.

RICOEUR, P. Percurso do reconhecimento. São Paulo: Loyola, 2006.

MORAIS, Alexander Almeida A concepção de Charles Taylor de uma ética da autenticidade unida a uma política do reconhecimento. In: Revista Filosofia Capital. Vol.6. Edição 13, 2011, p. 3-10.

TAYLOR, C. As fontes do self. São Paulo: Loyola, 1997, p. 9-145.

The politics of recognition. In: GUTMANN, A (Ed). Multiculturalism: examining the politcs of recognition. Princeton: Princeton University Press, 1994, p. 2573.

Argumentos filosóficos. Ed. Loyola, 2000.

WINNICOTT, D. A família e o desenvolvimento individual. Tradução de Marcelo Brandão Cipola. São Paulo: Martins Fontes, 1983.

Da pediatria à psicanálise. Tradução de Davy Litman Bogomoletz. Rio de

Janeiro: Imago, 2000.

\begin{tabular}{|l|l|l|l|l|}
\hline Q Povista Dialectus & Ano 5 & n. 12 & Janeiro - Julho 2018 & p. 400-418 \\
\hline
\end{tabular}

